\title{
The role and uptake of private health insurance in different health care systems: are there lessons for developing countries?
}

This article was published in the following Dove Press journal:

ClinicoEconomics and Outcomes

4 March 2013

Number of times this article has been viewed

\author{
Isaac AO Odeyemi' \\ John Nixon ${ }^{2}$ \\ 'Senior Director and Head of Health \\ Economics and Outcomes Research, \\ Astellas Pharma UK Ltd, Chertsey, \\ UK; ${ }^{2}$ Teaching Associate in Health \\ Economics, Department of Economics \\ and Related Studies, University \\ of York, York, UK
}

Background: Social and national health insurance schemes are being introduced in many developing countries in moving towards universal health care. However, gaps in coverage are common and can only be met by out-of-pocket payments, general taxation, or private health insurance (PHI). This study provides an overview of PHI in different health care systems and discusses factors that affect its uptake and equity.

Methods: A representative sample of countries was identified (United States, United Kingdom, The Netherlands, France, Australia, and Latvia) that illustrates the principal forms and roles of PHI. Literature describing each country's health care system was used to summarize how PHI is utilized and the factors that affect its uptake and equity.

Results: In the United States, PHI is a primary source of funding in conjunction with tax-based programs to support vulnerable groups; in the UK and Latvia, PHI is used in a supplementary role to universal tax-based systems; in France and Latvia, complementary PHI is utilized to cover gaps in public funding; in The Netherlands, $\mathrm{PHI}$ is supplementary to statutory private and social health insurance; in Australia, the government incentivizes the uptake of complementary PHI through tax rebates and penalties. The uptake of PHI is influenced by age, income, education, health care system typology, and the incentives or disincentives applied by governments. The effect on equity can either be positive or negative depending on the type of PHI adopted and its role within the wider health care system.

Conclusion: PHI has many manifestations depending on the type of health care system used and its role within that system. This study has illustrated its common applications and the factors that affect its uptake and equity in different health care systems. The results are anticipated to be helpful in informing how developing countries may utilize PHI to meet the aim of achieving universal health care.

Keywords: social health insurance, developing countries, private health insurance, health care systems

\section{Introduction}

To reduce an inequitable and often catastrophic reliance on out-of-pocket (OOP) payments to finance health care, ${ }^{1}$ various forms of social health insurance (SHI) are being introduced by a number of developing countries in response to the call of the World Health Organization (WHO) to move towards universal health care. ${ }^{2}$

SHI schemes in developing countries commonly take the form of contributions from employees and employers linked to earnings for the formal sector, and various forms of private or community-based health insurance are potentially available for the informal sector and members of rural communities. ${ }^{3,4}$ Developing countries that have recently introduced or expanded SHI include China, Vietnam, Colombia, Mexico, 
Nigeria, Ghana, South Africa, and Tanzania., ${ }^{4,5}$ Although there is evidence that some of these schemes are having a positive impact in reducing OOP payments and improving equity in access to health care, ${ }^{6,7}$ gaps in provision and coverage are common and will need to be addressed. ${ }^{8}$

Such gaps can only be met by one or a combination of the following: (1) OOP payments, (2) general taxation, or (3) private health insurance (PHI). While progressive taxation and SHI systems potentially offer the most equitable means of financing health care, ${ }^{9} \mathrm{PHI}$ is a feature of almost all Organization for Economic Co-operation and Development (OECD) countries ${ }^{10}$ and is recognized as an important option for developing countries. ${ }^{11}$

PHI can be classified under three general categories: (1) free market health insurance, (2) controlled market health insurance, and (3) medical savings accounts (MSAs). In applications where PHI is optional, it is referred to as voluntary health insurance (VHI). ${ }^{12}$ PHI can also play several different roles with regard to health care systems. In some applications, it acts as the primary source of financing, while in other countries it operates in a supplementary role to cover gaps in health care coverage. In still other countries, PHI is complementary to publicly financed health care through cost-sharing arrangements. PHI (VHI) may also be substitutive to a public system whereby subpopulations are allowed, or encouraged, to opt out of the statutory system and use comprehensive PHI as an alternative. ${ }^{10,13}$

In free-market PHI, although mostly regulated through legislation, actuarially fair premiums are applied whereby high-risk individuals pay higher premiums than those at low risk. In controlled-market PHI, the government imposes regulations and mechanisms to equalize risk across the community by applying community ratings such that premiums are set according to criteria such as age of entry or membership of a defined community. ${ }^{14}$

MSAs, alternatively known as health savings accounts (HSAs), offer a means of providing PHI cover for emergencies and a separate fund for elective treatments and OOP expenditure through regular savings. ${ }^{12}$

Insurance companies providing PHI take various measures to manage risk associated with two phenomena: moral hazard and adverse selection. ${ }^{12}$ Moral hazard refers to the behavior of the insured and potentially results in an additional quantity of potentially unnecessary health care being demanded. Measures to control moral hazard include co-payments and deductibles, which vary according to the nature of premiums and cover provided. Adverse selection (of high risks) arises from asymmetric information whereby individuals are able to purchase insurance at premiums below their actuarially fare rate. Insurance companies typically address this by screening potential clients regarding preexisting conditions, age, and lifestyle characteristics. ${ }^{12}$

With this background in mind, the aim of this study is to provide an overview of the application of PHI in an informative sample of different health care systems. The factors that affect the uptake of PHI are also discussed with the objective of informing policymakers in developing countries regarding how PHI can be part of the mix of funding arrangements that can be applied in moving towards universal health care.

\section{Methods}

After reviewing health care systems according to their typology (tax-based, SHI, PHI, and mixed public/PHI), ${ }^{12}$ and the application of PHI within them, ${ }^{10}$ the countries selected as representative case studies were: the US, the UK, The Netherlands, France, Australia, and Latvia. Latvia was included as it is a former Eastern Bloc country and offers some important insights regarding its use of PHI since this transition.

Descriptions of countries' health care systems were obtained from the European Observatory on Health Systems and Policies' Health Systems in Transition series, ${ }^{15}$ the latest Commonwealth Fund's study of international profiles of health care systems, ${ }^{16}$ and other relevant literature. PubMed was searched to locate additional studies that reported the factors that affect the uptake of PHI.

For each country, summary statistics on health care spending from the OECD Health database ${ }^{17}$ and World Bank ${ }^{18}$ were included for the following variables: total health expenditure as a percentage of gross domestic product (GDP), per capita health expenditure, public health expenditure, private OOP expenditure, and PHI spending as a percentage of total expenditure.

\section{Results}

The summary data for each country selected are provided in Table 1 and are used to augment case study descriptions in the following sections.

\section{The United States}

The US is categorized as a "mixed system"12 as it has a large free-market PHI (VHI) system as a primary source of financing, which operates in conjunction with tax-funded public programs for specified groups. Although PHI plays a major role, Table 1 shows it accounts for less than half (35\%) of total health expenditure, while public expenditure accounts 
Table I Health care expenditure and example PHI formats in selected countries

\begin{tabular}{|c|c|c|c|c|c|c|}
\hline Country & $\begin{array}{l}\text { THE } \\
\text { (\% of GDP) } \\
2010\end{array}$ & $\begin{array}{l}\text { Per capita } \\
\text { HE (US\$) } \\
2010\end{array}$ & $\begin{array}{l}\text { Public HE } \\
\text { (\% of THE) } \\
2010\end{array}$ & $\begin{array}{l}\text { OOP } \\
\text { (\% of THE) } \\
2007\end{array}$ & $\begin{array}{l}\text { PHI } \\
\text { (\% of THE) } \\
2007\end{array}$ & $\begin{array}{l}\text { Form and role of principal PHI } \\
\text { Main system of funding }\end{array}$ \\
\hline \multirow[t]{2}{*}{ Australia } & 8.7 & 4775 & $67 \%$ & 19.8 & 8.2 & Complementary (controlled) \\
\hline & & & & & & Universal tax-based with health levy \\
\hline \multirow[t]{2}{*}{ France } & 11.9 & 4691 & 78.7 & 7.2 & 13.4 & Complementary (free market) \\
\hline & & & & & & Statutory SHI \\
\hline \multirow[t]{2}{*}{ Latvia } & 6.7 & 718 & 64.1 & $\mathrm{n} / \mathrm{a}$ & $5.0^{\mathrm{a}}$ & Complementary and supplementary (free market) \\
\hline & & & & & & Tax-based statutory SHI \\
\hline \multirow[t]{3}{*}{ The Netherlands } & 11.9 & 5593 & 75.6 & 6.0 & 6.2 & Complementary (controlled) \\
\hline & & & & & & and supplementary (free market) \\
\hline & & & & & & Statutory controlled $\mathrm{PHI}$ and $\mathrm{SHI}$ \\
\hline \multirow[t]{2}{*}{ UK } & 9.6 & 3503 & 81.3 & 11.1 & $2.9 \%$ & Supplementary (free market) \\
\hline & & & & & & Universal tax-based \\
\hline \multirow[t]{2}{*}{ US } & 17.9 & 8362 & 44.9 & 13.5 & 35 & Primary source (free market) \\
\hline & & & & & & Partial tax-based system \\
\hline
\end{tabular}

Notes: Sourced from 2010 data, The World Bank; ${ }^{18}$ 2007, OECD Health database, 201 I; ${ }^{17}$ Boyle for UK OOP data; ${ }^{22}$ abased on an estimate using 200 I data. ${ }^{27}$

Abbreviations: GDP, gross domestic product; HE, health expenditure; n/a, data not available; OOP, out-of-pocket private expenditure; PHI, private health insurance; THE, total health expenditure.

for $44.9 \%$. OOP payments are second highest in the sample, at $13.5 \%$. Although the US has the highest health expenditure in the world, ${ }^{16}$ public insurance and PHI coverage is highly fragmented, with multiple private and public sources and gaps in coverage rates across the US population. ${ }^{16}$

MSAs were initially authorized in the US using a combination of consumer-driven health plans - usually low-cost insurance for catastrophic events with high deductibles - and MSA accounts to fund OOP expenditure and elective care. This PHI arrangement postulates the prudent use of health care and thus potentially controls for moral hazard. However, users may avoid seeking treatment or utilizing preventive health care measures in preserving their savings. A modified employee-only version, the HSA, is being adopted in the US since the passing of HSA legislation in 2003 as part of the Medicaid prescription drug act. ${ }^{12}$

Publicly funded health care is principally delivered via the Medicare and Medicaid programs, although a number of other programs are available for specific sectors of the population. ${ }^{19}$ Medicare is a national program that covers approximately $95 \%$ of those aged 65 years and older in addition to many disabled people receiving social security. Medicaid is a state-run program, with matching federal funding, that provides health care coverage to certain vulnerable individuals or groups on low incomes. Each state establishes its own eligibility criteria, range of services covered, and tariffs, within broad criteria specified by the federal government. ${ }^{12}$ However, the poorest individuals are not covered unless they belong to specified groups, such as children less than 6 years of age or pregnant women from families with incomes below $133 \%$ of the federal poverty level. ${ }^{12}$
Despite these arrangements, a significant proportion of the US population have no, or inadequate, health insurance..$^{20}$ In 2010, 81 million people (44\% of US adults) were uninsured or under-insured (having high medical expenditures relative to their incomes): this figure represents an increase of almost one-third from $2003 .^{20}$

In an attempt to reduce the number of uninsured Americans, the Affordable Care Act (ACA) was introduced in 2010 by the Obama Administration. ${ }^{20,21}$ The aim is to expand Medicaid coverage to include individuals with incomes below $133 \%$ of the federal poverty level, and provide assistance to limit premiums for those with incomes of up to $400 \%$ of the federal poverty level..$^{20,21}$ A recent study suggests that full implementation of the ACA could reduce the number of underinsured by up to $70 \% .^{20}$

This case study indicates that the use of nonstatutory and free-market PHI as a primary source of funding, with public provision for vulnerable groups, is expensive, complex, and associated with gaps in coverage. Achieving universal health care is being addressed through the ACA in the US, but substantial challenges remain.

\section{The United Kingdom}

The UK has a tax-based health care system that provides universal health care coverage through its National Health Service (NHS) with supplementary free-market PHI (VHI). Heath services in the UK are largely free at the point of use within the NHS and cover qualifying residents from "the cradle to the grave." It is the only option for many long-term chronic conditions as well as accident and emergency care. ${ }^{22}$ 
Funding sources include direct and indirect taxes plus national insurance contributions. However, some services that are not covered are funded by user charges, direct OOP payments, or through PHI. ${ }^{22}$ Table 1 shows that total health expenditure is $9.6 \%$ of GDP, and public funding accounts for $81.3 \%$ of total health care spending. OOP payments constitute the largest single element of private expenditure, accounting for $11.1 \%$ of total health care expenditure. ${ }^{22} \mathrm{PHI}$ in the UK is taken out by about $12 \%$ of the population ${ }^{16}$ and accounts for only $2.9 \%$ of total health expenditure (Table 1).

PHI is utilized mainly to avoid some of the perceived limitations of the NHS. These include relatively long hospital waiting lists, limited choice of specialist provider, and potentially lower standards of hospital facilities compared with PHI provision. ${ }^{12}$ It is also utilized to cover care no longer provided by the NHS such as optician services and cost sharing within dental care. In terms of those who purchase PHI, data suggest that individual and corporate purchasers account for approximately equal proportions of expenditure. ${ }^{22}$ The underlying stimulus behind supplementary PHI in the UK, therefore, is dissatisfaction with the public NHS, cost sharing, or in meeting gaps in provision.

\section{France}

France is a statutory SHI country that provides an example of complementary PHI in order to meet gaps in social security reimbursements. Health care coverage in France is now virtually universal at $99.9 \%$ as a result of the introduction of "couverture maladie universelle" (CMU) in 2000. ${ }^{23}$

While SHI seeks to cover the entire population, it does not cover $100 \%$ of expenditures that are paid using fee-forservice arrangements. To cover this gap, the vast majority (92\%) of the population has PHI (VHI) either through their employers or via means-tested vouchers. ${ }^{16,23}$ Only $6.8 \%$ of PHI is purchased by individuals. ${ }^{23}$

As can be seen in Table 1, France spends about $12 \%$ of its GDP on health care, which is one of highest percentages in the European Union (EU)..$^{19,24}$ Most of this (73.2\%) is classified as "social security" funding, and the remainder is general taxation. OOP expenditure is low in France (7.2\%), and per capita spending is relatively high (US\$4691). In addition to cost-sharing through coinsurance, which can be fully reimbursed by PHI (VHI), some co-payments associated with doctors' visits, prescription drugs, and hospital treatment are not reimbursed up to an annual ceiling of $€ 50$ (US\$70) to avoid catastrophic payments for health care and control for moral hazard. ${ }^{16}$
To assist the poorest in society, people with a taxable income of less than $€ 9020$ per year are exempt from paying SHI contributions, while those with incomes above this threshold pay $8 \%$ of their taxable income. In addition, free PHI coverage is offered to people with incomes below a defined ceiling ( $€ 7521$ as of January 2010 ); this covers $8 \%$ of the population. ${ }^{23}$

To facilitate access to PHI by people at the margin of the CMU income threshold, a voucher scheme, "aide pour une complémentaire santé," was established in 2004 for people whose income is below $120 \%$ of the CMU threshold. In 2010 , the amounts available under this scheme ranged from $€ 100$ per year for people aged less than 25 years to $€ 400$ for people aged over 60 years. This scheme covers about 5.3\% of the overall population. . $^{23,25}$

The case of France illustrates the added complexity of SHI, compared with tax-based universal systems, in that individuals and the government take many additional steps to achieve financial protection in health care and the nearuniversal coverage that is provided.

\section{The Netherlands}

The Netherlands was previously a statutory SHI country that utilized substitutive PHI for high income earners. Since being reformed in 2006, however, substitutive health insurance has been abolished. ${ }^{16}$ The reformed system now offers a good example of complementary and supplementary PHI (VHI) to statutory and controlled PHI operating in conjunction with an SHI component to provide comprehensive coverage.

As shown in Table 1, The Netherlands spends about 12\% of its GDP on health care and has the second highest per capita spending behind the US. Seventy-five percent of health expenditure is public, with a very low percentage of OOP contributions - the lowest in the sample at $6 \%$. PHI (VHI) accounts for only $6.2 \%$ of total health expenditure.

The health care system is financed by a "compartmentalized" system with two principal components. ${ }^{26}$ The first is longterm and disability care, which is funded by statutory SHI, regulated through the Exceptional Medical Expenses Act (Algemene Wet Bijzondere Ziektekosten; AWBZ). The second component consists of basic health insurance for short-term medical care, which is funded by compulsory and controlled PHI. Individuals pay a community-rated nominal premium and an income-dependent employer contribution, which is deducted directly from their wages; a health care allowance is available for lower income groups. There is competition between private health insurers, who can negotiate to a certain extent with health care providers on the 
price, volume, and quality of care delivered. They are also allowed to pay dividends to shareholders, unlike traditional SHI schemes which are not-for-profit. ${ }^{12}$

Most of the population purchases PHI (VHI) from the same health insurers who provide statutory coverage. The premiums and products of this insurance coverage are not regulated. This form of PHI covers, for example, dentistry and extra visits to a physiotherapist. In $2009,91 \%$ of people who were insured under the statutory schemes also had PHI (VHI). It should be noted that those with VHI do not receive faster access to any type of care, nor do they have more choice of specialist or hospital. ${ }^{16}$

Although health insurance is statutory, about $1 \%$ of the population (approximately 171,000 persons) is uninsured, mainly due to objections to insurance on religious grounds or for other reasons. Such individuals can purchase an insurance policy when they require care, but risk a penalty of $130 \%$ of total nominal premiums for the time that they were uninsured. ${ }^{26}$

The system of The Netherlands therefore illustrates a minor role for PHI (VHI) with a dramatic shift from its former SHI system to a reliance on compulsory and highly controlled PHI for short-term care. Like France, a complex set of arrangements is used to provide near-universal coverage of the population.

\section{Latvia}

Latvia offers a particularly useful example of PHI (VHI) in a complementary and supplementary role alongside a taxfunded statutory SHI system within a former Eastern Bloc country. A number of fairly radical changes have occurred since achieving membership of the EU in 2004.
The central Government is responsible for financing the SHI system through tax revenue, and additional funding comes directly from OOP payments and from PHI (VHI). As shown in Table 1, Latvia spends the lowest among the sample countries as a share of GDP (6.7\%), but this has shown a marked increase from only $3.4 \%$ of GDP in $2005 .{ }^{27}$ Latvia also has the lowest per capita spending of US\$718, which reflects the relative size of its economy and population compared with other countries in the sample. The public spending element accounts for about two-thirds of total health expenditure. The percentage of total health expenditure on PHI is estimated to be 5\% (Table 1). The proportion of total health care expenditure accounted for by PHI increased to this figure from $1.8 \%$ in 1997 and appears to have stabilized since the 2001 estimate. $^{27}$

Interest in PHI (VHI) was first shown in 1996, following the introduction of user charges, and the market has increased rapidly since then as shown in Figure 1; using Latvian currency data and 1997 prices it can be seen that premiums rose from about Ls 3 million in 1997 to about Ls 18 million in 2008, while claims rose from about Ls 2 million to Ls 11 million over the same period. Although comparative data for OOP expenditure as a share of total expenditure are not available for 2007, data for OOP spending as a percentage of private expenditure show a very high figure (97.3\%) using 2010 figures. This compares less favorably with the UK (62\%), France (33.1\%), The Netherlands (38\%), Australia (64\%), and the US (25.2\%). ${ }^{18}$

Supplementary PHI is used to cover health care services and/or prescription drugs which are not financed by the statutory system, such as dentistry for adults, routine health checkups needed for specific job security requirements,

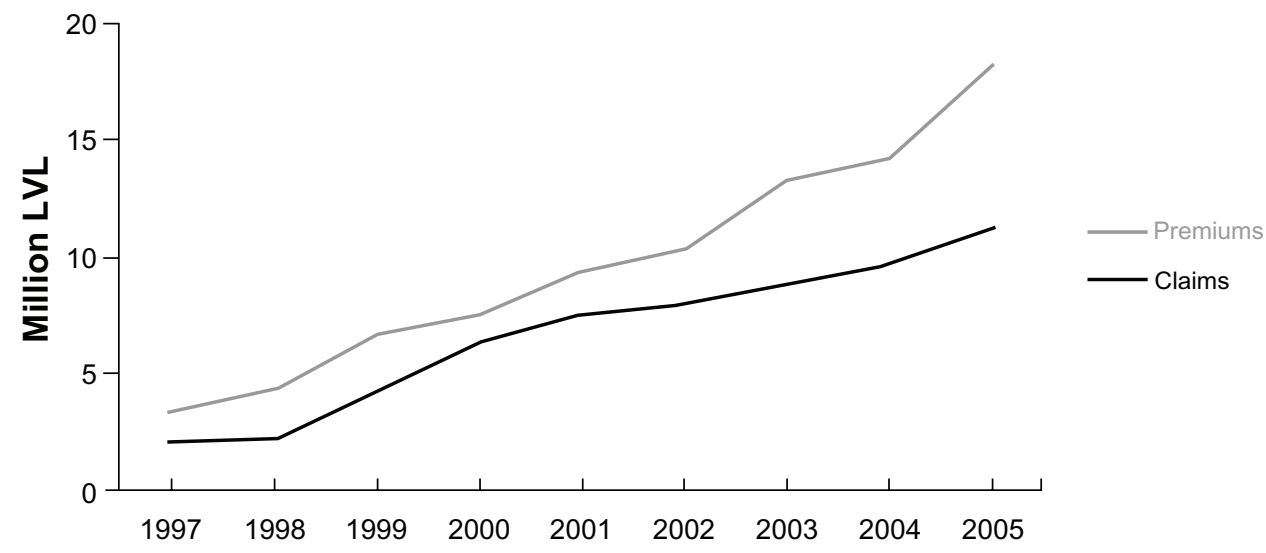

Figure I Growth of private health insurance in Latvia between 1997 and 2005.

Note: Prices are shown in real terms, deflated by use of the consumer price index for 1997 prices.

Data from Tragakes E, Brigis G, Karaskevica J, et al. Latvia: health system review. Health Syst Transit. 2008; 10:I-253. (C) with permission. ${ }^{27}$

Abbreviation: LVL, Latvia currency. 
physiotherapy and massage, rehabilitation, and some vaccines. Complementary PHI (VHI) schemes cover only OOP charges such as optician services, hearing aids, and prostheses. Actuarially fair premiums are calculated according to companies' tariffs, based on the purchaser's age and health status. ${ }^{27}$

The observed growth in supplementary and complementary PHI (VHI) and OOP expenditure in Latvia reflects the inability of public funding to meet an increasing demand for health care services. ${ }^{27}$

\section{Australia}

Australia offers an example of how incentives are utilized to encourage the uptake of controlled PHI for some aspects of care (hospital) as an alternative to a universal tax-based system. This is a form of complementary PHI, ${ }^{16}$ as users are not allowed to opt out of their tax commitments to fund the public system.

As shown in Table 1, Australia spends a comparatively low percentage of GDP on health at under $9 \%$, but achieves per capita spending above other countries that spend less as a share of GDP. This feature reflects a relatively strong economy. The health care system is mainly financed through general taxation as public spending on health is $67 \%$, while OOP expenditure is the highest in the sample at almost $20 \%$. Funding also includes a small statutory insurance levy and PHI accounts for a relatively low figure of $8.2 \%$.

The public, tax-funded national health insurance scheme, Medicare, provides universal access to subsidized medical services, subsidized pharmaceuticals, and free hospital treatment as a public patient. People can also take out controlled PHI to cover or partially cover the financial costs of hospital treatment as private patients to facilitate quicker access to elective surgery with private patient status, or to cover or partially cover dental and other allied health services. ${ }^{16,28}$

In 2000, the government introduced Lifetime Health Cover (LHC), an initiative designed to encourage people to take up PHI at an early age and maintain their cover throughout their lives. ${ }^{29}$ Under LHC, early uptake of PHI is rewarded with lower premiums (in recognition of the fact that younger people are less likely to require hospital treatment than older people), and premiums are eligible for age-related tax rebates of $30 \%-40 \%$, which increase with age. ${ }^{29,30}$ Insurers cannot refuse coverage, and premiums are community-rated to equalize risk. ${ }^{29}$

Evidence suggests that these initiatives have increased uptake of PHI by $50 \%$, and decreased the average age of purchasers. ${ }^{31}$ Some commentators suggest, however, that the penalty of $2 \%$ per year for delaying insurance, introduced as part of the LHC plan, is too low to be effective. ${ }^{32}$ Findings suggest that some insurers flouted community rating systems by screening older consumers into more expensive plans. The LHC may not, therefore, have increased health care access via $\mathrm{PHI}$ as much as intended.

In spite of these mixed messages, Figure 2 provides an informative representation of estimated hospital coverage in Australia, expressed as a percentage of the population, assuming that the current policy of LHC and a 30\% tax rebate on private health insurance premiums is either maintained or withdrawn. As can be seen, the projected percentage if LHC is maintained is an approximately $20 \%$ higher uptake, which is sustained over the period 2004-2042.

The case study of Australia is informative as it illustrates that some governments seek to shift health care financing

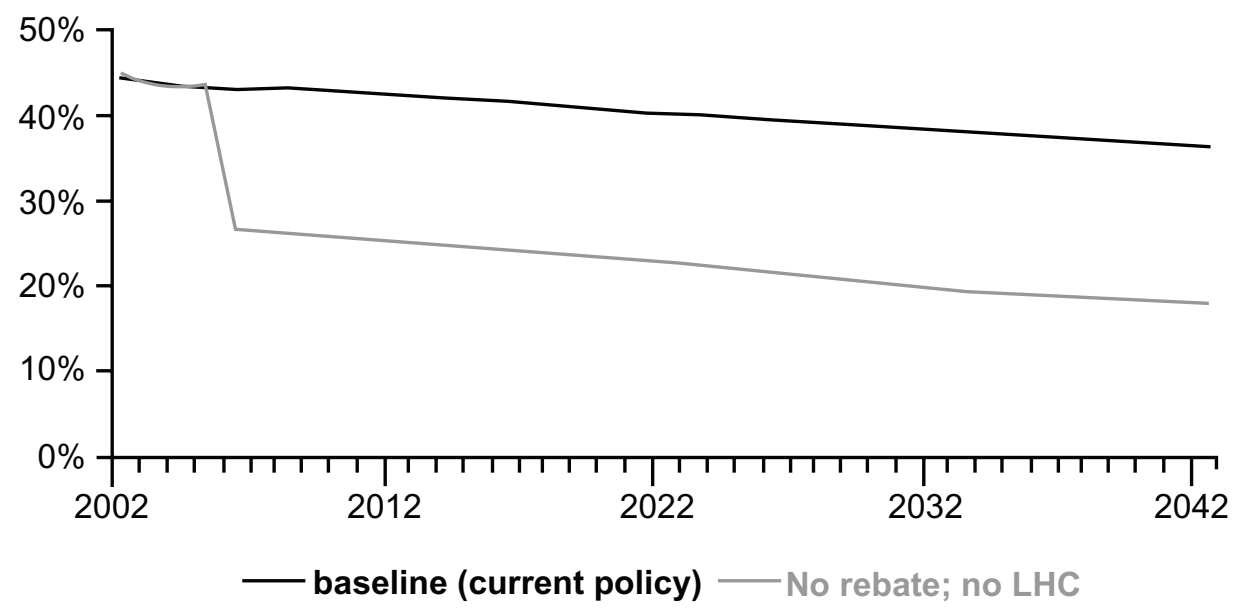

Figure 2 Estimated private health insurance hospital coverage in Australia - Lifetime Health Cover plus $30 \%$ tax rebate maintained or withdrawn. Econtech Pty Ltd, ${ }^{30}$ reproduced with permission. Abbreviation: LHC, Life-time Health Cover. 
away from general taxation. The study used for Figure 2 has estimated that if LHC and the tax rebate were withdrawn, the decreased use of PHI would increase projected public spending on health care by $0.5 \%$ of GDP by $2042 .{ }^{30} \mathrm{PHI}$ with sufficient controls and risk equalization, therefore, provides a potentially more equitable form of private health care in comparison with free-market PHI.

\section{Discussion}

The case studies presented in this paper have illustrated the wide range of applications and roles that PHI plays within a representative sample of countries that utilize, between them, the principal categories of health care systems according to their methods of financing health care. For countries considering the potential of PHI in improving equity in financing and access to health care, and addressing gaps in provision, it would be beneficial to consider the factors that affect its uptake and impact on equity, as outlined in the following.

The first points of relevance are whether or not PHI is statutory or voluntary, and whether it is free market or controlled with risk equalization. In statutory PHI with risk equalization as found in The Netherlands, uptake is high but not $100 \%$, and defaulters face a penalty if they purchase PHI only when needed or if they abstain. In Australia, positive and negative incentives exist to encourage uptake of controlled but voluntary PHI, with a focus on equity through measures such as community rating with risk equalization. In the case of the US, however, PHI (VHI) plays a primary role alongside Medicare or Medicaid, with a large proportion of the population uninsured or underinsured in the face of actuarially fair premium assessments. Achieving universal coverage under these conditions is a challenge which the Obama Administration is seeking to address. ${ }^{19,20}$

The uptake of PHI is clearly also influenced by health care system typology. The case study of the UK illustrates that long waiting times to access secondary care has been a significant cause of user dissatisfaction with its NHS. ${ }^{33,34}$ Similarly, the increase in PHI in Latvia during the last decade can largely be attributed to the inability of public funding to meet a rising demand for services coupled with the introduction of regressive OOP payments. ${ }^{27}$ In Australia, evidence also confirms that long waiting times for elective procedures has increased the probability of PHI uptake..$^{35}$ In statutory SHI and PHI systems the issue is not usually long waiting lists or a perceived need to use alternative providers, but rather with gaps in reimbursement or services, as illustrated by France and The Netherlands. Analyses of these countries indicate the complexity of responses using either taxation and/or PHI in order to achieve universal or near-universal coverage of the population.

Another important factor that affects uptake is socioeconomic status. In many countries, PHI (VHI) has been predominantly purchased by high-income groups, ${ }^{10,13,36}$ which can lead to inequalities in access. ${ }^{10,13,36}$ In the US, evidence confirms that low income is an important factor contributing to under-insurance, ${ }^{20}$ and conversely, higher incomes are associated with greater uptake of PHI. ${ }^{37}$ In a UK study covering the period from 1997 to 2000, income was a principal determinant of uptake of $\mathrm{PHI},{ }^{36}$ and there is evidence to suggest this remains the case..$^{22}$ Evidence regarding access to PHI in France also indicates a correlation with income, particularly affecting the elderly. ${ }^{23}$ Socioeconomic status has also been shown to be an important factor determining PHI uptake in Latvia. ${ }^{27}$ Similarly, an Australian study found a strong association between high rates of PHI cover and high socioeconomic status. ${ }^{38}$ Proxies of lower income, such as lower educational achievement or presence of mental health problems, have also found to be associated with lower uptake of PHI. ${ }^{37,39,40}$ There is some evidence, however, that PHI uptake in lower income groups may increase in the future if initiatives, as exemplified in the case of Australia, are actively adopted. ${ }^{41}$

Age has also been shown to be a factor affecting uptake of PHI. In the UK, for example, age was identified as a major determinant of PHI uptake and may reflect both increasing disposable income and greater concern about acquiring timely access to health care among older working people. ${ }^{36}$ As a result, older patients in the UK often pay full user charges to obtain access to health care, with one study finding that $30 \%$ of people aged over 75 years pay OOP user charges for private operations in England and Wales. ${ }^{42}$ In contrast, the Australian " 45 and Up" study reported higher uptake of private insurance among younger individuals incentivized by tax and lifetime cover incentives. ${ }^{43}$ In the US, one study found a "graying" of the PHI market as older, high-income users increasingly predominate. ${ }^{44}$ However, older people may find free-marked PHI difficult to obtain because actuarially fair premiums are higher than in younger people. MSAs, as a form of incentivized PHI, have been particularly popular in Asian countries with a strong savings ethos, such as Singapore, but their replication in other settings with very different health care systems and socioeconomic characteristics has been shown to be problematic. ${ }^{45}$

Although an in-depth analysis of the impact of PHI on equity is beyond the scope of the present study, it is clearly an important consideration for policymakers. Concerning equity 
in financing, the seminal work of Wagstaff et $\mathrm{al}^{9,46}$ offers some useful insights. Their analysis, although relating to the 1980s and 1990s, showed the UK to have, overall, a progressive system of financing, with PHI having a progressive effect; the US exhibited an overall regressive effect, and free-market PHI was shown to be regressive; France was progressive overall, with $\mathrm{PHI}$ having a regressive effect; the SHI systems with substitutive PHI (such as The Netherlands at that stage) were shown to be regressive overall, but substitutive PHI itself was progressive. Although no similar data are available for Australia, the use of controlled PHI with community-rating, life-time cover premiums mean the application of PHI is likely to be progressive, but the financial cost to the government of non-means tested rebates may well dampen this effect - estimated in 2011 to be A $\$ 4.5$ billion (US\$4.7 billion) annually. ${ }^{16}$

In terms of equity in access to health care, it should be noted that the benefits provided by some forms of supplementary and complementary PHI accrue exclusively to those who are covered by it. Furthermore, recent mortality data in the USA suggest that a lack of access to quality medical care appears to be responsible for widening the mortality gap between groups of higher education (a proxy for income) and lower education. ${ }^{47}$ If access to quality care, in terms of early diagnosis and appropriate treatment, is generally available only through PHI coverage, then this would suggest expansion of PHI to improve the overall quality of health care may be a productive development.

It is therefore possible to conclude that PHI can have either a positive or negative impact on equity depending on its application. However, the principal benefit of any form of PHI is protection against financial barriers to health care. Well run schemes may thus reduce OOP expenditures, which place a disproportionate burden on low-income individuals and therefore especially applicable to developing countries. ${ }^{11}$ Reducing a reliance on OOP expenditures is the major hurdle to be overcome in developing countries as many have OOP expenditures three or four times that of the highest country in the sample used in the present study. The WHO has quantified this impact in its 2010 Report; OOP expenditures of $60 \%-70 \%$ of total health expenditure result in $2 \%$ of the population becoming impoverished and $3.5 \%$ facing financial catastrophe. ${ }^{2}$ Moreover, informal economies, unemployment, self-employment, and aging populations with diminishing workforces may limit the available revenue from social insurance contributions and tax-based funding. ${ }^{13}$ Most of these factors and also the cost of premiums have a major limiting impact in developing countries, which often have a majority of the population living in abject poverty and are striving under many pressures to achieve universal health care. ${ }^{48}$

In terms of the limitations of our study, we acknowledge that forming strong conclusions from case studies has some shortfalls and we have intentionally selected specific countries with the aim of illustrating the common applications of PHI. As a financing mechanism, PHI also has a number of other components that we have not addressed. These include premium costs and collection methods, the impact on equity of variations in benefits packages, the payment mechanism used to reimburse providers, and the impact of different financing methods on health outcomes. In developing countries, the impact on equity regarding external donor funding to support weak health care financing may also be substantial as it is reported to be up to $80 \%$ in some countries. ${ }^{2}$ Too strong a reliance on donor funding is known to have adverse effects such as dampening the supply-side efforts of governments in financing health care. ${ }^{2}$ They should seek to increase internal and progressive methods of funding through general taxation and SHI where feasible, but also consider the role of PHI for specific groups to relieve pressure on public systems, as illustrated in the present case studies. These issues could beneficially form the basis of future studies in this area of analysis.

\section{Conclusion}

This study has illustrated the common applications of PHI in a representative sample of countries and how it has the potential to act as a primary source of funding or fill gaps in SHI, statutory PHI, or tax-based systems. Free market PHI (VHI) as a primary source is associated with large gaps in uptake and high overall cost. In countries where the public health care system provides universal access to a broad range of services, free-market PHI has a predominantly supplemental role in facilitating faster access to health care or in meeting gaps in services. In other countries, PHI is complementary to the public system, covering services or reimbursements that are partially funded by the public system. In other countries, controlled-market PHI is mandatory but requires risk-equalization mechanisms and a high degree of government intervention to ensure equity, with positive and negative incentives being effective in encouraging its uptake.

The uptake of PHI depends on many factors that include the makeup and performance of the public health care system, socioeconomic factors such as income, education, and age, 
and incentives from the government. The effects of PHI on equity in financing and access may be either positive or negative depending on the format and role of PHI. While developing countries face major challenges in attaining the goal of universal health care, PHI is playing a role in many emerging systems and is likely to develop further into the future under a mix of financing arrangements. The findings of this study are intended to be helpful to policymakers as they determine an appropriate mix of arrangements to finance health care and move towards universal coverage.

\section{Acknowledgments}

Paul Revill, Research Fellow at the Centre for Health Economics, University of York, UK, provided comments in revising this manuscript. Dr Michael Shaw (Bioscript Stirling Ltd) provided medical writing support, which was funded by Astellas Pharma Europe Ltd.

\section{Disclosure}

This study was funded by Astellas Pharma UK Ltd, UK. IAOO is an employee of Astellas Pharma UK Ltd. JN received consultancy fees from Astellas Pharma UK Ltd.

\section{References}

1. McIntyre D, Garshong B, Mtei G, et al. Beyond fragmentation and towards universal coverage: insights from Ghana, South Africa and the United Republic of Tanzania. Bull World Health Organ. 2008;86(11): 871-876.

2. The World Health Organization. The world health report - Health systems financing: the path to universal coverage. Geneva: World Health Organization; 2010.

3. nhis.gov.gh [homepage on the Internet]. National Health Insurance Scheme; 2012. Available from: http://www.nhis.gov.gh. Accessed December 26, 2012.

4. nhis.gov.ng [homepage on the Internet]. National Health Insurance Scheme; 2012. http://www.nhis.gov.ng. Accessed December 26, 2012.

5. Wagstaff A. Social health insurance reexamined. Health Econ. 2010;19(5):503-517.

6. Akazili J, Gyapong J, McIntyre D. Who pays for health care in Ghana? Int J Equity Health. 2011;10:26.

7. Nguyen HT, Rajkotia Y, Wang H. The financial protection effect of Ghana National Health Insurance Scheme: evidence from a study in two rural districts. Int J Equity Health. 2011;10:4.

8. Metiboba S. Nigeria's National Health Insurance Scheme: the need for beneficiary participation. Res J Int Stud. 2011;22:51-56.

9. Wagstaff A, van Doorslaer E, van der Burg H, et al. Equity in the finance of health care: some further international comparisons. J Health Econ. 1999;18:263-290.

10. Organisation for Economic Co-operation and Development. Private health insurance in OECD countries. Policy brief: OECD; 2004. Available from: http://www.oecd.org/dataoecd/42/6/33820355.pdf. Accessed September 20, 2012.

11. Sekhri N, Savedoff W. Private health insurance: implications for developing countries. Bull World Health Organ. 2005;83:127-134.

12. Folland S, Goodman AC, Stano M. The Economics of Health and Health Care, 6th ed. New Jersey: Pearson Prentice Hall; 2010.

13. Thomson S, Foubister T, Mossialos E. Financing health care in the European Union: challenges and policy responses. World Health Organization; 2009 .
14. McLeod H, Grobler P. The role of risk equalization in moving from voluntary private health insurance to mandatory coverage: the experience in South Africa. Adv Health Econ Health Serv Res. 2009;21:159-196.

15. Health Systems in Transition (HiT) series [webpage on the Internet]. London: European Observatory on Health Systems and Policies. Available from: http://www.euro.who.int/en/who-we-are/partners/ observatory/health-systems-in-transition-hit-series. Accessed December 26, 2012.

16. Thomson S, Osborn R, Squires D, Reed SJ. International Profiles of Health Care Systems, 2011. New York: The Commonwealth Fund; 2011. Available from: http://www.commonwealthfund.org/ /media/ Files/Publications/Fund\%20Report/2011/Nov/1562_Squires_Intl_ Profiles_2011_11_10.pdf. Accessed December 26, 2012.

17. Organisation for Economic Co-operation and Development. OECD Health Data. http://www.oecd.org/health/healthdata. Accessed Sep 2011.

18. The World Bank. World Bank Health Data. http://data.worldbank.org/ topic/health. Accessed Oct 2012.

19. Squires DA. The US health system in perspective: a comparison of twelve industrialized nations. Issue Brief (Commonw Fund). 2011;16: $1-14$.

20. Schoen C, Doty MM, Robertson RH, Collins SR. Affordable Care Act reforms could reduce the number of underinsured US adults by 70 percent. Health Aff (Millwood). 2011;30:1762-1771.

21. Oberlander J. Health care policy in an age of austerity. $N$ Engl J Med. 2011;365:1075-1077.

22. Boyle S. United Kingdom (England): health system review. Health Syst Transit. 2011;13(1):1-483, xix-xx.

23. Chevreul K, Durand-Zaleski I, Bahrami S, Hernández-Quevedo C, Mladovsky P. France: health system review. Health Syst Transit. 2010; 12:1-291.

24. European Commission. Healthcare statistics [webpage on the Internet]. Available from: http://epp.eurostat.ec.europa.eu/statistics_explained/ index.php/Healthcare_statistics. Accessed December 26, 2012.

25. Rapport d'activité 2009. Fonds de financement de la protection complémentaire de la couverture universelle du risqué maladie, CMU, Paris. http://www.cmu.fr/rapports-activite.php. Accessed December 26, 2012.

26. Schäfer W, Kroneman M, Boerma W, et al. The Netherlands: health system review. Health Syst Transit. 2010;12:1-229.

27. Tragakes E, Brigis G, Karaskevica J, et al. Latvia: health system review. Health Syst Transit. 2008;10:1-253.

28. Healy J, Sharman E, Lokuge B. Australia: health system review. Health Syst Transit. 2006;8:1-158.

29. Lifetime health cover [webpage on the Internet]. Canberra: Department of Health and Ageing; 2010 [updated October 24, 2012]. Available from: http://www.health.gov.au/internet/main/publishing.nsf/content/ health-privatehealth-lhc-providers-general.htm. Accessed Oct 2012.

30. Econtech Pty Ltd, Harper Associates, Hagan P. Easing the pressure: the Intergenerational Report and private health insurance. Melbourne: Econtech Pty Ltd; 2004.

31. Ellis RP, Savage E. Run for cover now or later? The impact of premiums, threats and deadlines on private health insurance in Australia. Int J Health Care Finance Econ. 2008;8:257-277.

32. Vaithianathan R. A critique of the private health insurance regulations. Aust Econ Rev. 2004;37:257-270.

33. Blendon RJ, Schoen C, DesRoches C, Osborn R, Zapert K. Common concerns amid diverse systems: health care experiences in five countries. Health Aff (Millwood). 2003;22:106-121.

34. Klein R. The troubled transformation of Britain's National Health Service. N Engl J Med. 2006;355(4):409-415.

35. Johar M, Jones G, Keane M, Savage E, Stavrunova O. Waiting times for elective surgery and the decision to buy private health insurance. Health Econ. 2011;20(Suppl 1):68-86.

36. King D, Mossialos E. The determinants of private medical insurance prevalence in England, 1997-2000. Health Serv Res. 2005;40: 195-212. 
37. Cohen RA, Martinez ME. Consumer-directed health care for persons under 65 years of age with private health insurance: United States, 2007. NCHS Data Brief. 2009; 15:1-8.

38. Glover J, Tennant S, Duckett S. The geographic distribution of private health insurance in Australia in 2001. Aust New Zealand Health Policy. 2009;6:19.

39. Leach LS, Butterworth P, Whiteford H. Private health insurance, mental health and service use in Australia. Aust N Z J Psychiatry. 2012;46: 468-475.

40. Paccagnella O, Rebba V, Weber G. Voluntary private health insurance among the over 50s in Europe. Health Econ. Epub February 7, 2012.

41. Moorin R, Holman CD. The influence of federal health care policy reforms on the use of private health insurance in disadvantaged groups. Aust Health Rev. 2006;30:241-251.

42. Williams B, Whatmough P, McGill J, Rushton L. Patients and procedures in short-stay independent hospitals in England and Wales, 1997-1998. J Public Health Med. 2000;22:68-73.

43. Banks E, Jorm L, Lujic S, Rogers K. Health, ageing and private health insurance: baseline results from the 45 and Up Study cohort. Aust New Zealand Health Policy. 2009;6:16.
44. Keenan PS, Cutler DM, Chernew M. The 'graying' of group health insurance. Health Aff (Millwood). 2006;25:1497-1506.

45. Dong W. Can health care financing policy be emulated? The Singaporean medical savings accounts model and its Shanghai replica. J Public Health (Oxf). 2006;28(3):209-214.

46. Wagstaff A, Van Doorslaer E. Equity in health care finance and delivery. In: Culyer AJ, Newhouse JP, editors. Handbook of Health Economics. New York: Elsevier; 2000.

47. Cutler DM, Lange F, Meara E, Richards-Shubik S, Ruhm CJ. Rising educational gradients in mortality: the role of behavioral risk factors. $J$ Health Econ. 2011;30:1174-1187.

48. Onwujekwe O, Onoka C, Uzochukwu B, Hanson K. Constraints to universal coverage: Inequities in health service use and expenditures for different health conditions and providers. Int J Equity Health. 2011; 10(1):50.

\section{Publish your work in this journal}

ClinicoEconomics \& Outcomes Research is an international, peerreviewed open-access journal focusing on Health Technology Assessment, Pharmacoeconomics and Outcomes Research in the areas of diagnosis, medical devices, and clinical, surgical and pharmacological intervention. The economic impact of health policy and health systems organization also constitute important areas of coverage. The manuscript management system is completely online and includes a very quick and fair peer-review system, which is all easy to use. Visit http://www.dovepress.com/testimonials.php to read real quotes from published authors.

Submit your manuscript here: http://www.dovepress.com/clinicoeconomics-and-outcomes-research-journal 